\title{
NO QUIERO SER SEGUA O AFAN DE PERENNIDAD DE BELLEZA
}

\author{
Virginia Fonseca
}

Juzgar una obra dramática como lectores es más difícil que hacerlo como espectador; porque aquellos pueden saltarse algunos signos del escenario, mientras que el espectador los tiene todos ante sí.

La segua, escrita por el dramaturgo nacional, Alberto F. Cañas, se halla articulada por tres diferentes códigos: el literal, que corresponde a la historia amorosa de Encarnación; el paralelo, recoge las mutaciones maravillosas de esa historia; el derivado, conlleva un intento de trascendentalización.

En la materialidad de la pieza teatral, tales códigos aparecen entremezclados. Sin embargo, puede afirmarse que predomina el literal, en que personajes, situaciones y hechos tienen un significado único.

He aquí algunos casos de este tipo:

Los comentarios que los vecinos de Cartago hacen sobre el próximo regreso de don Félix Fernández.

La petición de Camilo a don José Manuel para visitar a Encarnación.

La lucha entre Camilo y Petronila ante la casa de los Sanchos.

Sin perjuicio, pues, de que los códigos se den separados como en los ejemplos precedentes, se mezclan hasta en una misma escena, hasta en un mismo parlamento, como cuando Encarnación habla de embrujamiento, de que ella es la segua que enlo queció al teniente Corona, y de la necesidad de evitar que le ocurra otro tanto a Camilo de Aguilar. En esos casos coinciden los códigos literal y paralelo.

El menos frecuente es el código derivado - muy explicable tratándose de una comedia- en el cual se observa cómo la protagonista busca los recursos para retener su juventud y belleza.

A lo largo del suceder se designan realidades objetivas de primer grado, en íntimo contacto con el aspecto fáctico, es decir, aquello que ocurre en escena ante los ojos del espectador, como los encuentros entre Encarnación y Camilo o entre Camilo y Petronila, para citar pocos ejemplos.

Las realidades objetivas de segundo grado son menos numerosas; tienen carácter de relato, como la explicación de María Francisca sobre el embrujo de José Corona, la versión del mismo asunto hecha por José Manuel a Camilo, la canción de los dos mozos a modo de resumen lírico de la historia de la protagonista o algunos brevísimos monólogos que andan por allí (1).

Realidades puramente literarias hay también unas cuantas. Sirvan de ejemplo: la expedición de Camilo para buscar minas de oro; el acto de abandono de Petronila por parte de Camilo.

La historia amorosa de esta comedia 
descansa en un triple proceso de seducción en que el objeto perseguido es siempre el mismo: la hija de José Manuel Sancho. José Corona, Camilo de Aguilar y Félix Fernández son los pretendientes sucesivos.

Cuando comienza la obra ya han terminado las relaciones con el teniente Corona; pero las alusiones a éste sirven para crear el clima de lo maravilloso. Acaba ese noviazgo siendo un proceso frustrado a causa de las perturbaciones que afectan a Corona.

En el segundo proceso de seducción están implicados Camilo y Encarnación. El padre de la muchacha parece tolerar estas nuevas relaciones, aunque sutilmente va cambiando de parecer. Le cuenta al presunto yerno el hecho de que la joven cree que ella es la segua, además de que antes le había dicho:

\section{José Manuel.-}

Bueno es que usted se entere de que no soy amigo de favorecer a nadie. Nadie debe contar conmigo para nada. Que cada uno camine solo. Esto es muy importante que usted lo sepa (2).

La relación con Camilo es tormentosa, pues aunque con las reservas dichas, José Manuela Sancho permite el cortejo a su hija; aunque Manuela especie de tercera, contribuye al acuerdo de esta pareja, surgen obstáculos poderosos: Petronila Quesada y María Francisca. Aquélla, rival de Encarnación, ha vivido siempre de atrapar a los hombres, yahora sus inclinaciones van por Camilo. María Francisca finge simpatía por Encarnación mientras averigua el rumbo de los intereses afectivos de ésta, y le aconseja luego que se aparte de Camilo. Finalmente, José Manuel se opone a las relaciones de su hija con Aguilar, por la reputación de éste como galán aventurero amigo de pendencias. $\mathrm{Y}$ como si todo lo anterior fuera poco, Encarnación teme convertirse en segua y desdeña definitivamente a su actual enamorado.

En el proceso tercero -como parcialmente en el segundo-se mezclan los códigos literal y paralelo. Don Félix logra su propósito: ser aceptado por Encarnación. Quizá ella se decide, más que por el dinero y las comodidades que pueda proporcionarle el caballero, por la circunstancia de ser ciego. La vanidad de Encarnación, o mejor aún, su narcisismo, estima que sólo el invidente conservaría de ella la hermosa imagen de sus quince años. Ahora ella tenía veintitrés y él rondaba los sesenta.

Estos tres procesos de seducción constituyen el núcleo de la intriga; lo más tangible de ella, sobre todo a nivel de superficie. Pero conforme se cala en la obra, se advierte que la superstición es la base del código paralelo. De otro modo, literalmente hablando, la hija de José Manuel no es sino una muchacha, un tanto perturbada, cuyas relaciones amorosas se frustran con los dos primeros pretendientes; paralelamente, uno de los resultados de ese hecho, es que la protagonista acepta, como justificación del suceder, que sus pretendientes y ella quedan embrujados. Todas las obras de Cañas ofrecen personajes con situaciones anómalas desde el punto de vista psicológico, con lo cual se establece un interesante juego entre el ser y el parecer.

El código derivado descansa sobre una relación de semejanza bajo la fórmula "como si", eje de la conducta futura de la protagonista. Encarnación decide casarse con don Félix, pues la ceguera de éste le servirá como si" le fuera dado fijar la hermosura de sus quince años.

Los dos últimos códigos, paralelo y derivado, son los que se hallan más íntimamente ligados. Aquel se encuentra sostenido por pocos personajes, pero cobra intensidad porque tiene el soporte de la protagonista y sus conflictos.

A partir del momento en que Encarnación acepta la posibilidad de las brujerías, se identifica con la segua.

Encarnación.-

¿Quién se le apareció al teniente José Corona?

¿Quién es la única mujer bella con quien anduvo el teniente José Corona en Cartago? Yo. Y me amaba tanto, que no habria atendido requerimiento de otra. Si montó una mujer bella en la grupa de su yegua, tiene que haber sido a mí (3).

Y más adelante prosigue:

Encarnación.-

...Camilo se encontrará con la segua en 
un camino solitario, y esa segua seré yo aunque no me dé cuenta (4).

Esta motivación será la causa del rechazo a Camilo.

También pertenecen a este clima maravilloso el conjuro de María Francisca para que se amen el hidalgo y Petronila, y la danza de los machos cabríos, escena entre grotesca, sensual y satánica.

Otros personajes, aunque tienen conciencia de que no hay tales encantamientos, se ven implicados en el anómalo caso de Encarnación. Don José Manuel explica a Camilo de Aguilar que la joven, en su ingenuidad, cree que un pretendiente suyo no puede poner los ojos en otra mujer. Por eso, "al llegar la noticia del embrujamiento de la segua, hâ dado en la flor de afirmar que no pudo ser embrujo, si no fue por obra de Encarnación Sancho, única mujer bella con que topó el teniente Corona en Cartago (5)". Manuela oscila entre la aceptación y el rechazo del encantamiento cuando va a pedir ayuda para su niña a Fray Diego. El sacerdote lo atribuye todo a un trastorno mental.

Cabe entonces preguntarse cuál o cuáles son los significados de la segua en este contex to dramático.

1.- Lo que dice la conseja popular: una mujer hermosísima que transforma su rostro en cara de caballo para sorprende a los galanes trasnochadores.

2.- La segua es una mujer, ya sea Encarnación o cualquier otra, o "el hechizo de la carne", como afirma José Manuel. Por eso sentencia María Francisca que todas las mujeres son seguas.

3.- En vista del valor precedente, se explica el último sentido que le da Encarnación: lo desagradable y feo de la mujer; lo que pudiera causar repulsión al hombre. Por eso añade que no quiere ser segua, es decir, ni vieja, ni fea: "Nunca me verán el rostro horrible de vieja. Nunca verán en mí a la segua" (6).

Después de llegar a este sentido del término, lógica y dramáticamente se capta por qué es don Félix el pretendiente favorecido por la muchacha: el ciego no podrá verla envejecer; jamás mirará en ella la segua; será una manera de hacer perdurar su juventud y belleza.

En el plano de la intriga, el deseo de no convertirse en segua puede interpretarse como vanidad y aun como egolatría; pero según el código en que esto se ubique, podría mirarse como intento de vencer los límites del hombre, de conquistar un absoluto bajo la apariencia de eterna belleza. Como el ser existencial se halla preso en la cárcel del tiempo y del espacio, para evadirse de ella tiene necesariamente que acudir a recursos sobrenaturales: evasión vertical, como la de los místicos; o a medios maravillosos de evasión horizontal. La segua ha adoptado esta última dimensión.

Se puede dar el caso de que el mensaje tenga diferente significado, según que lo reciban los personajes o el público. Ello sucede con la conducta de la protagonista, quien piensa así: José Corona enloqueció por haber visto a la segua; yo soy la mujer más bella de Cartago; luego, yo tengo que ser la segua. El espectador sabe que esta lógica es inadmisible, de tal suerte que el soporte lógico es un absurdo, pero sirve de sustento a la comedia en cuanto equívoco, la cual salta desde lo grotesco hasta el intento de elevarse a una sentencia general: todas las mujeres son seguas si albergan lo desagradable de la vida.

Sabido cuál es el sentido último de ser o no ser segua, puede observarse que Encarnación busca conscientemente un proceso de mejoramiento, el cual consiste en conquistar la permanente belleza.

Don Félix ha dicho:

"Mientras yo viva (...) veré tu rostro bellísimo, el mismo de cuando cumpliste quince años, aunque yo me haga viejo, y aunque tu te hagas vieja..."(7).

E interrumpe ella para sintetizar la detención más allá de las fronteras del espacio y del tiempo.

Encarnación.- Es cierto. Para usted, mi imagen es inmóvil (8).

No se pierda de vista que el mejoramiento de Encarnación implicará la degradación de Camilo, pues éste verá frustrados sus deseos. 
Los otros personajes cumplen sus funciones, pero sin tener conciencia de estar contribuyendo o no al mejoramiento de Encarnación.

Don Félix es el mejorador, lo cual sólo es posible por su estado de invidente: "Los ciegos somos los guardianes de tesoros cambiantes", dice él. "Siempre me verá bella" - exclama la muchacha- y como corrigiéndose, agrega, "siempre me creerá bella" (9). El juego semántico transforma el ver exterior en ver interior, por lo cual él puede sentenciar: "Tengo una Encarnación para mí", circunstancia también maravillosa.

Camilo quiere reconquistar a la joven. Ella, aunque lo ama, resiste el impulso de permanecer a su lado. Camilo es, pues, el obstructor del proceso de mejoramiento, pues si hubiera sido "aceptado, ello significaría que el amante la vería envejecer, y consecuentemente, perdería la belleza.

Por la misma razón, Manuela habría frustrado el mejoramiento de Encarnación, si la cita que propicia para Camilo y su joven amada hubiese culminado con la reconciliación.

Por el contrario, Petronila y José Manuel sí contribuyen al proceso de mejoramiento. Aquella como ayudante, puesto que al preservar a Camilo para si, evita que Encarnación sea segua; José Manuel actúa como comejorador, al permitir que su hija tome el pretendiente que le parezca, sin imponerle directamente su voluntad.

Gráficamente este proceso de mejoramiento se representa así:

Proceso de mejoramiento desde el punto de vista de Encarnación.

Otros personajes que quedan sin mencionar en estas relaciones pueden agruparse con los ya citados: junto a Camilo, el teniente José Corona; con Petronila va María Francisca, quien acusa cierto sentido premonitorio con respecto al destino de Camilo; también los tres muchachos que danzan en el campo forman parte de la comparsería maravillosa en torno a la función de ayudante que tiene Petronila. Fray Diego y Manuela caben juntos; Baltasara marcha bien con José Manuel, pues aunque como esposa pide explicaciones, acaba por aceptar las razones del cabeza de familia.

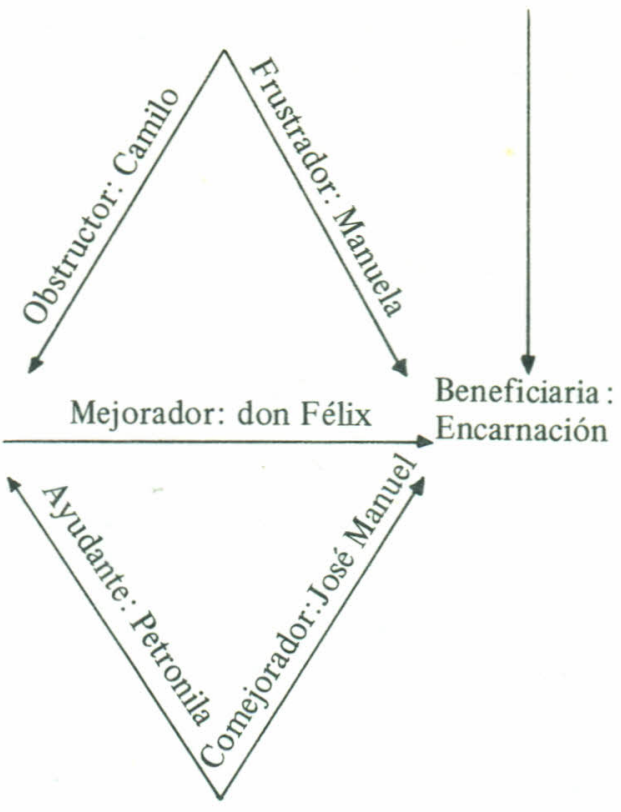

Quedan pendientes los personajes que contribuyen a dar la tipología del Cartago de mil setecientos y tantos, entre los que hay señores e indios, de los cuales casi todos comentan los sucesos que afectan a la familia de los Sanchos o en alguna oportunidad dan noticia de los fuera de escena o realidades solamente literarias.

Examinando lo que La segua tiene de fabulación, lo mismo que sus niveles de realidad, resta ver cuáles son las funciones de mayor frecuencia. Obligada en todas las obras está la función designativa que sirve para presentar objetos, personas, sucesos y procesos, por lo cual implica lo cognoscitivo y lo referencial. Se trata del Cartago colonial en donde se destaca la casa de José Manuel Sancho, la calle que rodea, sus paredes blancas, el piso de ladrillo, arcones, sillas de madera, imágenes religiosas; la celda del convento de capuchinos; el campo, la noche, la hoguera; todos estos objetos forman el marco para las peripecias.

Personas de distintas calidades representan las diferentes categorías sociales, las cuales se reconocen por las respectivas ocupaciones: familias de alcurnia como la de la protagonista, sus pretendientes y vecinos importantes; la india, pardos, trabajadores, el lazarillo de don Félix, Manuela: éstos son los pobres; los que viven de artes brujeriles son Petronila y María Francisca. 
Con estos personajes se teje la historia cuyos sucesos y procesos han sido aludidos al hablar de la fábula.

De las otras funciones se destaca de modo especial la prosódica, perceptible no sólo en el texto primario (pieza literaria) sino también en el secundario (acotaciones); muchas veces implícita y otras explícita, pero asociada siempre a los estados de conciencia de los personajes. El mayor número de variantes corresponde a Encarnación. También hay que incluir aquí las canciones.

Las funciones quinésica y proxémica están muy relacionadas. La primera se refiere al movimiento en general, y la otra, a las variedades de movimiento que expresan distancia.

En general pareciera que como el texto no se recarga con indicaciones sobre el aspecto funcional, deja campo abierto a la iniciativa del director y de los intérpretes.

Por último, la función fática, aquella que afirma o detiene la comunicación es decisiva para el desarrollo de la obra, según que acentúe o relaje los contactos entre los elementos susceptibles de relacionarse. A modo de ejemplo, véase la intriga amorosa desde el punto de vista de Petronila, en las relaciones antagónicas entre ésta, María Francisca y Encarnación.

- María Francisca dice a Encarnación que la locura de José Corona fue provocada por la segua.

- Encarnación declara a María Francisca que por influjo maléfico de ésta y de Petronila, la primera se transforma en segua.

- María Francisca predice a Petronila que no poseerá a Camilo para siempre.

- Cuando Camilo abandona a Petronila, ésta lucha contra él hasta darle muerte

Es una especie de clímax y anticlímax representados por el esfuerzo de Petronila y María Francisca por la posesión de Camilo (el elemento maravilloso contribuye a acentuar el contacto entre Petronila y Camilo), y luego la ruptura entre estos enamorados (se relajan los contactos entre Petronila y Camilo).

Hasta aquí se ha hablado de los signos del texto dramático. Si se pasa ahora a los del escenario, se verá que éstos proceden tanto del texto literario como de las acota- ciones. Pero antes caben dos referencias, de Breyer una, y de Appia la otra, ambas sobre el espacio teatral.

El hombre - piensa Gastón Breyer- a partir de su sitio de espectador, instrumentaliza el espacio al usarlo en diversas direcciones; en consecuencia no es un vacío, sino un lleno, latente y vivo (10). Adolphe Appia, gran escenógrafo precursor de muchos adelantos técnicos del teatro de hoy, afirma que para concebir el espacio hemos de pensar en la línea como trayecto de un punto a otro. El movimiento de los personajes va creando la espacialidad de la obra, lo mismo que los obstáculos que dificulten esas líneas (11). Se trata de una concepción dinámica y funcional.

Entre los signos del escenario en $L a$ segua, predominan los de cáracter directo para crear el ambiente colonial: casa, calle, celda de Fray Diego y otros más. Sólo unos pocos son indirectos, es decir, que además de representar lo que son tienen una significación segunda, como la ceguera de don Félix; además de defecto físico, constituye el vehículo con que la protagonista sobrepasa la acción del tiempo y fija la belleza y juventud; la noche oscura y sin estrellas es el marco propicio cuya tenebrosidad sugiere lo diabólico de la escena en que se lanza el conjuro para unir a Camilo con Petronila; lo mismo puede decirse de la hoguera en torno a la cual se abrazan estos dos amantes; la danza de los tres mozos en la orgía de los machos cabríos simboliza la sensualidad.

Por último, el telón corrido separa lo que fue la historia amorosa de Encarnación de las interpretaciones de los hechos que se suceden a través del tiempo; el telón es la barrera entre la ficción y la crítica.

De los demás elementos escenográficos, está de más indicar que la utilería debe contribuir a crear la atmósfera colonial, lo mismo que el vestuario aunque no aparezca especificado. En cuanto al uso de luces, invariablemente se emplea el oscurecimiento para sugerir la presencia de la noche.

Las funciones de los signos escénicos contribuyen a crear la espacialidad, sin la cual no habría teatro. Se destacan de modo muy especial lo quinésico y lo proxémico. Ya se sabe que el movimiento se advierte con 
las líneas que trazan los desplazamientos de los personajes, al cual se pueden añadir los gestos, mutaciones y diferentes distancias que adoptan los intérpretes.

Quede para el final de las presentes observaciones sobre La segua lo que el autor ha llamado estrambote. Según las preceptivas se entiende por tal el conjunto de versos añadidos al final de un soneto. La pieza teatral podría haber terminado con el viaje de los nuevos desposados. Sin embargo, aunque no prosigue la fábula, la acción se prolonga con un añadido o estrambote, que enjuicia lo sucedido a la familia Sancho en el Cartago de mil setecientos y pico.

Menos se puede hablar de epilogo, porque no da más noticias sobre la suerte de los personajes, sino que solamente los critica. De allí resulta que se puede decir que este estrambote es un acercarse al teatro épico, y en especial a la técnica del distanciamiento. He aquí algunas evidencias de ello: Afán de despertar en el espectador la actividad intelectual. Ya se dijo que la cortina separaba la ficción de la actitud crítica. Esta se inicia con los comentarios de don Eustaquio y don Rafael contra el señor Sancho. A partir de ese momento puede apreciarse cómo el correr del tiempo deforma los hechos.

El espectador ya no está introducido en la acción, sino frente a ella. Lo factual de La segua ya está concluido y ahora sólo se busca una interpretación del hombre lo sus hechos), como objeto de investigación. El teatro épico apela a la evocación. El estrambote produce esa sensación por la presencia de personajes de diferentes tiempos: desde los coetáneos al suceder (don Eustaquio y don Rafael) hasta los más recientes, los estudiantes, cuyas inquietudes atestiguan la complejidad del mundo moderno.

El autor sabe rehuir el tono trágico -a pesar del crimen contra Camilo- y mantenerse en el terreno de la comedia. Hay bastante movilidad escénica, diálogo ágil, buen dominio del idioma; agrada el salto que da de la vieja leyenda popular de la segua a un plano maravilloso que aspira a convertirse en trascendente.

Sin embargo, queda algo que no acaba de ajustarse al gusto del lector o del espectador. Ello obedece a que la pieza no se resuelve con una sola técnica, sino que se halla dividida en dos porciones bien diferentes: la primera de ellas responde a un teatro tradicional (en el sentido de que no despierta actitud crítica); la segunda, constituida por el estrambote, busca procedimientos brechtianos. Si tal esfuerzo épico estuviese presente a lo largo de la obra y no sólo en el estrambote, éste no produciría el efecto de ser artificioso. Mas a pesar de estas apreciaciones, no se pierda de vista que el licenciado Cañas es el máximo cultor del teatro en Costa Rica y que cada obra suya es un interesante experimento dramático, de los cuales El luto robado conserva aún el primer lugar.

\section{NOT A S}

1. Vid. Alberto F. Cañas. La segua y otras piezas. San José, EDUCA 1974. pp.26,50.

2. Ibid, p.15.

3. Ibid, p.23.

4. Ibid, p.25.

5. Ibid, p.20.

6. Ibid, p. 54.
7. Ibid, p.29.

8. Ibid. p. 29.

9. Ibid, p. 29.

10. Gastón A. Breyer. Teatro: el ámbito escénico. Buenos Aires, Centro Editor de la América Latina S.A. 1968, p.10.

11. Cf. Coppeau, Appia y otros. Investigaciones sobre el espacio escénico. Comunicación 4. Madrid, Alberto Corazón Editor, 1970, p.58. 